\title{
Study on the Refined Teaching Management of College and the Effective Mechanism
}

\author{
Qin Chen, Suqun Duan, Fancai Zeng, Xiaorong Zeng, Qiong Zhao \& Kelin Liu \\ Academic Administration, Luzhou Medical College, Luzhou 646000, China \\ E-mail: zwxin626@163.com
}

Received: August 23, 2010 Accepted: January 10, 2011 doi:10.5539/ies.v4n2p72

The research is supported by the project of "Study on the Teaching Quality Management Mode of Medical College in the Refined Management Concept" of the Sichuan Provincial Higher Education Talent Cultivation Quality and Teaching Reform of 2009-2012 (No. 2009-288). (Sponsoring information)

\begin{abstract}
According to the requirement that the higher education of China in the new term needs new educational strategy "to enhance the teaching quality", the concept and the formation and operation of the effective mechanism of the refined teaching management of college are introduced in this article, to seek an optimal solution to enhance the teaching quality.
\end{abstract}

Keywords: Refined teaching management, Mechanism, Quality

\section{Introduction}

In the "National Medium and Long-term Educational Reform and Development Program", to enhance the quality is the core task of the reform and development of education, and in the national conference on education of 2010, "the management system and the work mechanism oriented by enhancing the quality are advocated to be established" (Zheng, 2010 \& Xinhua Net, 2010). It is obvious that in the national education strategy system, the management is the important guarantee for the college to pursue the "excellence", and the teaching management will be breakthrough point to enhance the teaching quality of education. Since the teaching level of undergraduate was evaluated, the teaching management of this college has experienced two big changes, and the first change was the change from the experienced teaching management to the standard teaching management through the evaluation, which was the base of the future development of the teaching management. The second change was the change from the standard management to the refined management. This change is the response of the educational strategy that the higher education of this college in new tern "takes enhancing the teaching quality as the core", with important theoretical meanings and practical values. The refined management in this article is not the usual enterprise refined management, because the output of enterprise is product, and the core of its refined management is to pursue the profit, but the output of college is talent and the talent cultivation is the first function of the college, so the core of the college refined management is to promote the sustainable development of human being (Wang, 2005).

\section{Definition and Source of the Refined Teaching Management}

\subsection{Definition}

Refined teaching management (shortened form: refined management) is the education development view taking enhancing quality as the core, and it is the load to pursue the excellent college culture, and it is a kind of excelsior thinking. Based on the scientific management, refined attitude, combination of science the people, it is the teaching management mode which improves the internalization and refining of the quality culture and achieves the maximum and optimal educational teaching quality, and its core is to promote the sustainable development of human being.

\subsection{Source}

The refined teaching management comes from traditional teaching management and the popular five classic management theories including the refined management, the comprehensive quality management, the people-oriented management, the learning organization, and the comprehensive risk management, and it uses the thinking modes of these management theories for references, combines with the social demands and the education teaching rules, and finally occurs in the college teaching management by the form of integrated innovation. 


\section{The Formation of the Effective Mechanism of the College Refined Teaching Management}

\subsection{Institutionalization of Refined Teaching Management}

The institutionalization of refined teaching management is to refine the methods and rules from various teaching activities, and transform these refined management abilities and methods into the common criterions and continually improve them. Immaterial management will be transformed into a kind of material mechanism and case. This mechanism could maintain, copy, and develop itself, and make the whole teaching organization to achieve the highest level. The institutionalization of the refined management includes three approaches, i.e. the yes/no, the standardization, and the institutionalization.

(1) The yes/no. The behaviors should be judged first according to the teaching rules of education, so those negative behaviors will be eliminated, which is the premise of the standardization.

(2) The standardization. According to judged behaviors, the positive behaviors will be induced, and corresponding standards could be extracted, and those negative behaviors are not directly related with the standardization.

(3) The institutionalization. To popularize standard behaviors, a kind of effective running mechanism must be formed, which is the institutionalization. Only the institutionalization could exert the real efficiency of the standard to the teaching unit.

In above three stages, the yes/no is the key part, so the college refined management starts from the yes/no, but it contains an important premise, i.e. the teaching mangers have strong evaluation judgment ability, which requires higher requirements about the education value view including the professional quality, the management content, and the technical content, for the teaching management group.

\subsection{Meanings}

First, the institutionalization of refined teaching management could help us to effectively grasp the actuality, discover the improved space, and obtain horizontal advantages and vertical advancements. Second, the solidification of ability and method will be the key for one teaching unit to obtain the middle and long-term core competitive force. Third, to transform experienced and technical management group into the knowledge and management group needs the professionalization of the management group. Fourth, the maximum teaching benefit could be obtained by the minimum investment. Fifth, the maximum ability will be normalized by the standardization, for example, once the maximum performance is obtained, and the highest level is achieved, it will be regarded as a target, and by the refined management and improvement, this target will be a normal level and state, and a normal ability. And this level with high performance must be sustained and improved endlessly.

\section{The Operation of the Effective Mechanism of the Refined Teaching Management}

A big deficiency exists in the past teaching reform, i.e. the teaching reform disjoints even interferes with the teaching management reform. To overcome this deficiency, the operation of the refined management effective mechanism should be emphasized. First, the teaching management system should focus on and serve for the teaching works. Second, the teaching reform should be integrated with the management reform. As viewed from the static content, the operation of the effective mechanism of the refined teaching management mainly involves four concrete contents and management problems in the teaching activity.

The first one is the refined management of the cultivation project generation process, and it is the core content in the effective mechanism of the refined teaching management, and the core content of the college course and teaching reform in all colleges. It is directly related with the diversification of the talent cultivation mode and the cultivation of the creative talents for Chinese colleges. The change of the talent cultivation mode requires that the generation process of the whole talent cultivation project should be changed correspondingly. But this change needs certain criterions which should be solidified by the system. That is the refined management of the generation process of the talent cultivation project, i.e. the core and most important part in the course management.

The second one is the resource allocation and management to guarantee the smooth execution of the cultivation project. In the allocation of various resources, the allocation of teachers, teachers' scientific research level, teaching skill and level, work attitude, and work rule are on the core state. The allocation of other resources includes the allocation of outlay, the allocation of teaching establishments and experiment equipments, and the allocation of books and materials. At the same time, the management of these resources and the allocation procedure is the key to ensure the smooth development of the allocation of various resources, and it is an important aspect in the refined teaching management mechanism.

The third one is the implementation and management of the cultivation project. The implementation of the cultivation project needs corresponding space and time, and certain flexibility. The teaching process is a quite 
complex process, and it is not only a cognition process, but a development process about students' body and heart, and the process that teachers and students explore the unknown world together, and in this process, teachers' teaching mode should be not only scientific, standard and common, but also artistic, creative, and individual. Therefore, the management of the teaching process should not only have uniform requirement and criterion, but also leave free and imagery space and time for teachers and students. A harmonious and loosen atmosphere and environment must be built in this part and guaranteed by the policy and system.

The fourth one the object served by the cultivation project and relative management problems. Student is the service object and the direct beneficiary of the teaching reform. Students' study habits, ideological concepts, and understanding bout the teaching reform are very important to obtain and solidify the result of the teaching reform. Colleges should orient the talent cultivation, and put the focus of the college work on cultivating high-quality students, and satisfy the requirement of students' body and heart development. Students and relative management are necessary part in the effective mechanism of the refined teaching management.

\section{Conclusions}

The refined teaching management is the teaching management to seek the breakthrough point of enhancing the teaching quality for the Medical College. To advance with the times in the concept of education internationalization, the refined management is an effective approach, and it will be a necessary ridge that colleges should step over in the future. In this article, the mechanism and operation of the refined teaching management is mainly introduced, and it is only one point of the refined management project for the Medical College, and the refined teaching quality management system and the application in the talent cultivation will be introduced in succession in the future, to comprehensively know the refined teaching management of colleges.

\section{References}

Baidu Net. (2010). Refined Management. [Online] Available: http://baike.baidu.com/view/583596.htm?fr=ala0_1(Jul 14, 2010)

Zhongqiu, Wang. Hongpiao, Wu. \& Xingwang, Liu. (2005). Refined Management. Beijing: Xinhua Press. May of 2005.

Xinhua Net. (2010). The National Conference on Education Takes Place, and Hu Jintao \& Wen Jiabao Make Important Speech. [Online] Available: http://news.xinhuanet.com/politics/2010-07/14/c_111954115_4.htm(Jul 14, 2010)

Ke, Zheng. (2010). National Medium and Long-term Educational Reform and Development Program (2010-2020). [Online] Available: http://www.scio.gov.cn/zggk/gqbg/2010/201008/t720862.htm(Aug 2, 2010) 